\title{
First record of Bertrana striolata (Arachnida: Araneae: Araneidae) in Amazonian Ecuador
}

\author{
Diego F. Cisneros-Heredia*, Ivan Carrazco-Montalvo \\ Universidad San Francisco de Quito USFQ, Colegio de Ciencias Biológicas y Ambientales COCIBA, Laboratorio de Zoología Terrestre, \\ Quito 170901, Ecuador \\ *Autor principal/Corresponding author, e-mail: diego.cisnerosheredia@gmail.com
}

Editado por/Edited by: César Zambrano, Ph.D

Recibido/Received: 2016/07/25. Aceptado/Accepted: 2016/12/03.

Publicado en línea/Published online: 2016/12/19. Impreso/Printed: 2016/12/27.

DOI:http://dx.doi.org/10.18272/aci.v8i1.790

\section{Primer registro de Bertrana striolata (Arachnida: Araneae: Araneidae) en la Amazonía de Ecuador Resumen}

Presentamos el primer registro de la araña tejedora Bertrana striolata en las tierras bajas de la Amazonía (este de los Andes) de Ecuador, basados en un espécimen colectado en la Estación de Biodiversidad Tiputini, provincia de Orellana, Ecuador. Previamente la especie era conocida en el país de solamente una localidad en las tierras bajas del Pacífico (oeste de los Andes).

Palabras Clave. Araña tejedora, bosque tropical, distribución, Neotropical, Orellana, Tiputini, Yasuní.

\begin{abstract}
We present the first record of the orb-weaver spider Bertrana striolata from Amazonian lowlands (east of the Andes) in Ecuador, based on a specimen collected at the Tiputini Biodiversity Station, province of Orellana, Ecuador. Previously the species was known in the country from just one locality on the Pacific lowlands (west of the Andes).
\end{abstract}

Keywords. Distribution, Neotropical, orb-weaver spider, Orellana, rainforest, Tiputini, Yasuní.

\section{Introducción}

Bertrana Keyserling, 1884 is a Neotropical genus of spiders that includes some of the smallest known araneid orb-weavers [1-2]. Up to date, 12 species of Bertra$n a$ have been described, but due to their small size, they are less often collected, and much remains to be discovered about its diversity and distribution [1-2]. Bertrana striolata Keyserling, 1884 has the broadest geographic range among all species of the genus, with records in Costa Rica, Panama, Colombia, Ecuador, Peru, Guyana, Brazil, Bolivia, and Argentina [1]. Despite its large range, B. striolata is known from broadly scattered localities, and most records come from Panama and Brazil [112]. In western Amazonia, B. striolata remains known from just four localities: one in Colombia (Bueva Vista) and three in Peru (Tingo María, Dantas La Molina,
Atalaya-Río Carbón) [1]. We present the first record of B. striolata from the Amazonian lowlands of Ecuador.

The voucher specimen is deposited in the collection of spiders of the Museo de Zoología (ZSFQ), Colegio de Ciencias Biológicas y Ambientales, Universidad San Francisco de Quito, Quito, Ecuador (patent No. 0062015-FAU-DPAP-MA). It is preserved in $70 \%$ ethanol with glycerine. Since species of the genus Bertrana are tiny and delicate spiders, we present black-and-white illustrations to offer clear details of its dorsal pattern and epyginium (with the same parameters standardised by Levi [1]. The specimen was examined and measured under an Olympus SZX16 research stereomicroscope and illustrations were made with an attached camera lucida. 


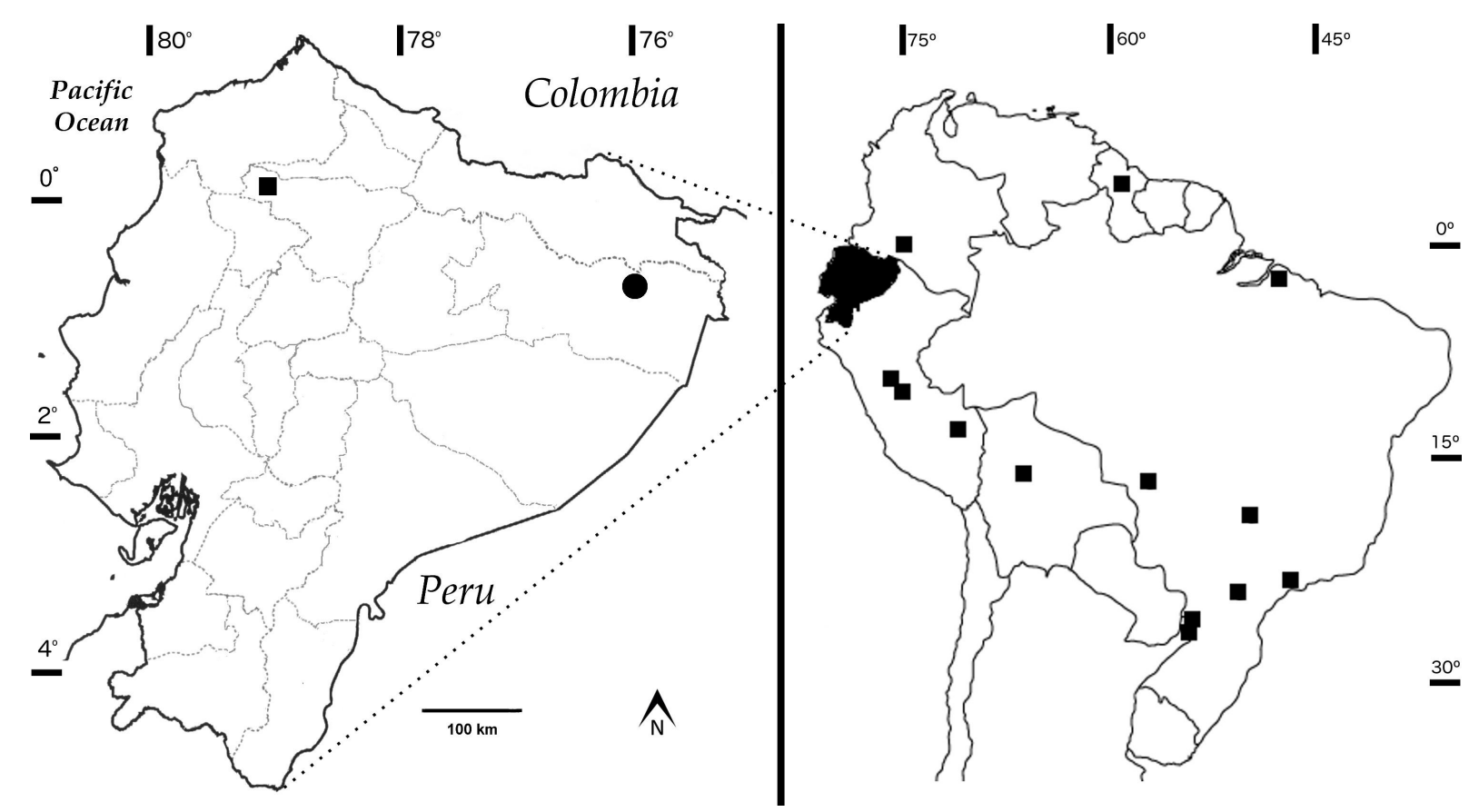

Figura 1: Map depicting known point localities of Bertrana striolata in Ecuador (left), and in South America (right). Squares = literature records (see text for references), circle = new locality in Amazonian Ecuador (Tiputini Biodiversity Station, province of Orellana).

A female Bertrana striolata (ZSFQ-Q053, Fig. 2) was collected at Tiputini Biodiversity Station TBS

$\left(0.618056{ }^{\circ} \mathrm{S}, 76.171944^{\circ} \mathrm{W}, 250 \mathrm{~m}\right.$, Fig. 1) on $24 \mathrm{Ju}-$ ne 2009. It was found on a vertical two-dimensional orb web (0,26 m diameter; $0,99 \mathrm{~m}$ above ground) on a bush at a gap in primary Varzea forest, sitting in the hub at about $17 \mathrm{~h} 30$. TBS is a scientific station located in the province of Orellana, Republic of Ecuador, ca. $280 \mathrm{~km}$ ESE from Quito, in the northern bank of the Tiputini River, part of the Napo and Amazonas rivers basins. Universidad San Francisco de Quito (Ecuador) established this station in 1995, in collaboration with Boston University (USA), as a centre of education, research and conservation. TBS is adjacent to the Yasuní National Park and it is part of the Yasuní Biosphere Reserve. TBS preserved ca. 650 hectares of primary forest, mostly Non-Flooded Lowland Evergreen forests, but narrow belts of Varzea (Lowland Evergreen forests seasonally flooded by white water rivers) and Igapó (Lowland Evergreen forests seasonally flooded by black water rivers) extend along the borders of the river, streams, and oxbow lake.

The specimen herein reported (Fig. 2) is identified as a member of the genus Bertrana by having sparse black pigment in the eye region, low soft carapace, widerthan-long abdomen, and small size ( $<5 \mathrm{~mm}$ total length) [1]. It clearly shows all diagnostic characters of female Bertrana striolata, including: carapace with black lines on a white dorsal background (without dusky marks), epigynum wider than long with a wider than long median plate in posterior view. No significant differences are found in coloration and genital morphology between our specimen and populations of other regions [1]. Our specimen is slightly larger (4.3 $\mathrm{mm}$ total length) than those reported by Levi [1], up to $3.8 \mathrm{~mm}$ in total length), but we regard this as intraspecific variation.

TBS is at ca. $148 \mathrm{~km}$ ENE from the closest known Amazonian locality of $B$. striolata (Buena Vista, department of Putumayo, Colombia [1]); and ca. $950 \mathrm{~km} \mathrm{~N}$ from the closest known Amazonian locality in Peru (Tingo María, department of Huánuco [1]). This specimen corresponds to the first record of $B$. striolata in Amazonian Ecuador, filling the gap between localities in the Amazonian lowlands of Colombia and Peru (Fig. 1).

In Ecuador, Bertrana striolata was previously known from a single locality on the Pacific lowlands (4 km NE of the town of Pedro Vicente Maldonado, $550 \mathrm{~m}$, province of Pichincha) based on two specimens collected in July 1988 [1]. To the best of our knowledge, our record also corresponds to the second locality of the species in the country, and the first record for the province of Orellana. The lack of previous records of this species in Ecuador is most certainly due to the absence of studies on the diversity of spiders in Ecuador, rather than to its low abundance or rarity. In fact, five species of Bertrana have been recorded in Ecuador: Bertrana elinguis, B. planada, B. striolata, B. poa, and B. urahua [1-2, 13]. Yet, nothing has been published about any of these spiders in Ecuador since their original descriptions. In general, knowledge on the diversity and natural history of the spider fauna of Ecuador is deficient. 


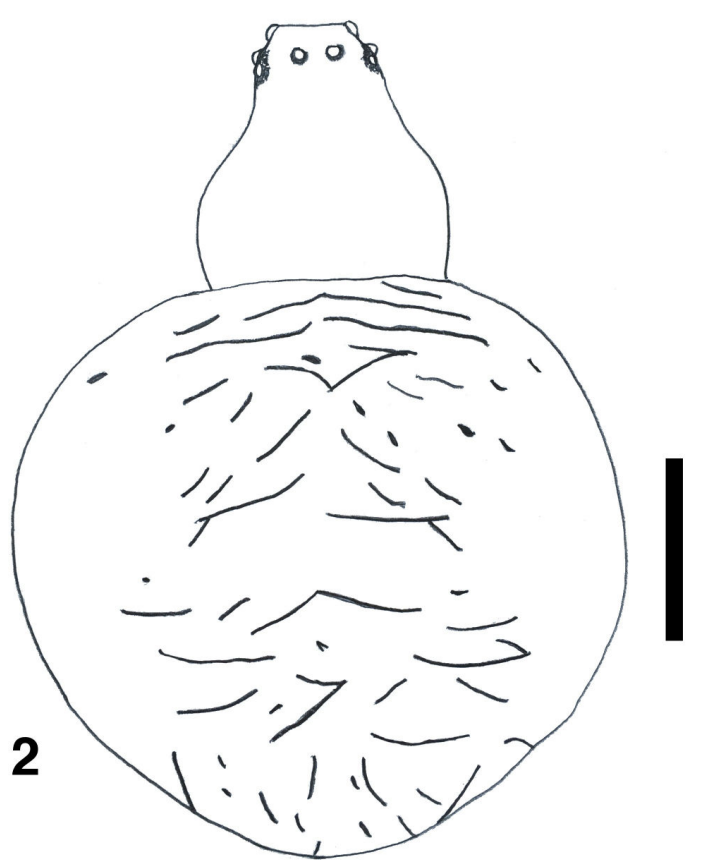

3

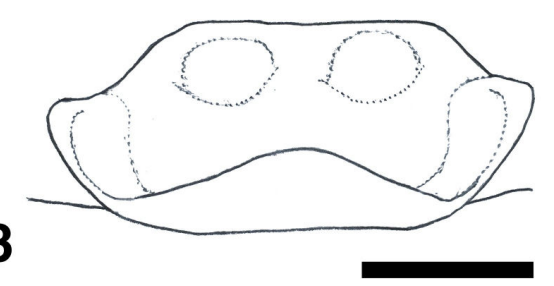

Figura 2: Bertrana striolata (ZSFQ-Q053, female, 4.3 mm total length) collected at the Tiputini Biodiversity Station TBS, province of Orellana, Ecuador. 2: Dorsal view (scale line $=1 \mathrm{~mm}$ ). 3: Epyginium in ventral view (scale line $=0,1 \mathrm{~mm}$ ).

\section{Acknowledgements}

We are grateful to Pablo Riera and Gabriel Muñoz for support during our work, and to two reviewers that commented on the manuscript of this paper. Universidad San Francisco de Quito, María Elena Heredia, and Laura Heredia provided financial support for our studies. This study is the first contribution of the research programme "Diversity of Orb-Weaver Spiders (Araneidae) in Ecuador", which aims to increase our knowledge on the diversity and biogeography of Ecuadorian araneids.

\section{Referencias}

[1] Levi, H. W. (1989). The Neotropical Orb-Weaver Genera Epeiroides, Bertrana and Amazonepeira (Araneae: Araneidae). Psyche, 96(1-2), 75-99. DOI: http://doi.org/ $10.1155 / 1989 / 658908$.
[2] Levi, H. W. (1994). New Species of Bertrana and Amazonepeira, Orb-Weaving Spiders from the Neotropics (Araneae: Araneidae). Transactions of the American Microscopical Society, 113(3), 229-241. DOI: http:// doi.org/10.2307/3226619.

[3] Buckup, E. H., Marques, M. A. L., Rodrigues, E. N. L., \& Ott, R. (2010). List of spiders species (Arachnida, Araneae) of the state of Rio Grande do Sul, Brazil. Iheringia. Série Zoologia, 100(4), 483-518. DOI: http:// doi.org/10.1590/S0073-47212010000400021.

[4] Caporiacco, L. D. (1948). Arachnida of British Guiana collected in 1931 and 1936 by Professors Beccari and Romiti. Proceedings of the Zoological Society of London, 118(3), 607-747. DOI: http://doi.org/10.1111/ j.1096-3642.1948.tb00402.x.

[5] Chavari, J. L., Cipola, N. G., \& Brescovit, A. D. (2014). Records of Spiders (Arachnida: Araneae) of the Parque Estadual Mata São Francisco, Paraná, Brazil. Check List, 10(6), 1435-1444. DOI: http://doi.org/10.15560/ 10.6.1435.

[6] Chickering, A. M. (1963). The Female of Bertrana hieroglyphica Petrunkevitch (Araneae, Argiopidae). Psyche, 70(2), 129-132. DOI: http://doi.org/10.1155/1963/ 30864 .

[7] Keyserling, E. (1884). Neue Spinnen aus America. V. Verhandlungen Der Kaiserlich-Königlichen Zoologisch-Botanischen Gesellschaft in Wien, 33, 649684. DOI: http://doi.org/10.5962/bhl.part.25328.

[8] Keyserling, E. (1893). Die Spinnen AmerikasEpeiridae- (Vol. II). Nürnberg: Verlag von Bauer \& Raspe (E. Küster).

[9] Nentwig, W. (1993). Spiders of Panama: Biogeography, investigation, phenology, check list, key and bibliography of a tropical spider fauna (Fauna and Flora Handbook No. 12). Gainesville: Sandhill Crane Press.

[10] Petrunkevitch, A. (1925). Arachnida from Panama. Transactions of the Connecticut Academy of Arts and Sciences, (27), 51-248.

[11] Podgaiski, L. R., Ott, R., Rodrigues, E. N. L., Buckup, E. H., \& Marques, M. A. de L. (2007). Araneofauna (Arachnida; Araneae) do Parque Estadual do Turvo, Rio Grande do Sul, Brasil. Biota Neotropica, 7(2), 197-212. DOI: http://doi.org/10.1590/ S1676-06032007000200023.

[12] Raizer, J., Japyassú, H. F., Indicatti, R. P., \& Brescovit, A. D. (2005). Comunidade de aranhas (Arachnida, Araneae) do pantanal norte (Mato Grosso, Brasil) e sua similaridade com a araneofauna amazônica. Biota Neotropica, 5(1A), 125-140. DOI: http://doi.org/10. 1590/S1676-06032005000200011.

[13] WSC. (2016, December). World Spider Catalog. Version 17.5 Natural History Museum Bern. URL: http:// wsc.nmbe.ch. 